\title{
2-AMINOBENZOYL-COA MONOOXYGENASE/REDUCTASE, A NOVEL TYPE OF FLAVOPROTEIN HYDROXYLASE
}

\author{
B. Langkau, S. Ghisla
}

Dept. of Biology, University of Konstanz, 7750 Konstanz, FRG

\author{
V. Massey \\ Dept. of Biol. Chem., University of Michigan, Ann Arbor, MI-48109, USA \\ G. Fuchs \\ Dept. of Appl. Microbiol., University of Ulm, 7900 Ulm, FRG
}

\section{Introduction}

Recently we reported on the unusual course of a reaction catalyzed by 2-aminobenzoyl-CoA monooxygenase/reductase from a Pseudomonas sp.(1). This enzyme catalyzes the insertion of one atom of oxygen into the aromatic moiety of the CoA substrate. This enzyme is uncommon in several aspects: a) It is the first flavin dependent hydroxylase to act on a CoA thioester as a substrate. b) it inserts a hydroxyl function into the para position of the aromatic amine and c) it catalyzes the reduction of an intermediate to yield a hydrogenated and hydroxylated product. In order to better understand the chemistry of this peculiar reaction course, and possibly to gain information on the general mechanism of flavin-dependent hydroxylation, we have studied some of the basic properties of this enzyme in comparison with the properties of some typical hydroxylases.

Results and Discussion

Spectral properties of the enzyme

2-Aminobenzoyl-CoA monooxygenase/reductase shares some common properties with the dehydrogenase-monooxygenase class of flavoproteins $(2,3,4)$. The enzyme does not exhibit any semiquinone formation during the course of either photoreduction (EDTA/light) or reduction 
with NADH and yields a fully reduced flavin spectrum. In analogy to all hydroxylases no formation of a sulfite-N(5)-adduct was observed upon incubating the enzyme with up to $20 \mathrm{mM}$ sulfite for $17 \mathrm{~h}$.

The addition of 2-aminobenzoyl-CoA causes significant alterations in the visible absorption of 2-aminobenzoyl-CoA monooxygenase/reductase. The absolute and difference absorbance spectra are shown in Figure 1A and B. A plot of \% ES-complex formed versus the equivalents of substrate added indicates half-site reactivity (Figure 2). 2-Aminobenzoyl-CoA primarily binds to one subunit of the dimeric enzyme tightly $\left(\mathrm{K}_{\mathrm{d}} \approx 1 \mu \mathrm{M}\right)$ and to the second subunit only weakly, and with only small spectral perturbations, which make it difficult to determine accurately the $\mathrm{Kd}$ value. This correlates with the observation of substrate inhibition in turnover experiments at [2-aminobenzoyl-CoA] $>150 \mu \mathrm{M}(5)$.
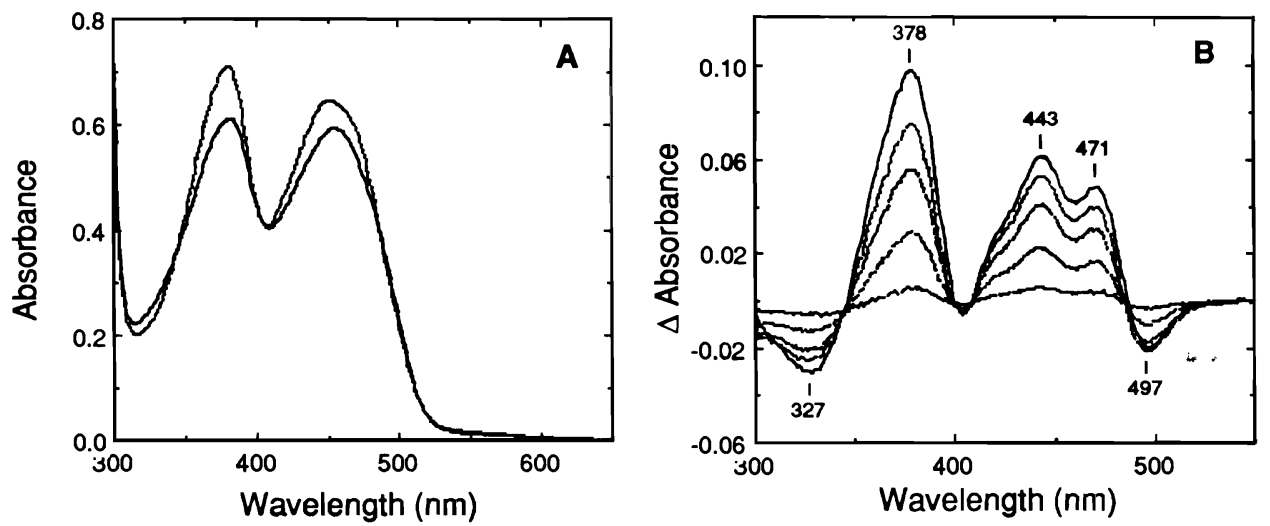

Figure 1. Spectrophotometric titration of 2-aminobenzoyl-CoA monooxygenase/reductase with 2-aminobenzoyl-CoA. Conditions: $52.6 \mu \mathrm{M}$ enzyme bound flavin, $50 \mathrm{mM}$ sodium phosphate, $\mathrm{pH} 7.4,0.1 \mathrm{mM}$ EDTA; temperature $4^{\circ} \mathrm{C}$. All spectra were recorded versus the corresponding concentration of substrate in the reference cuvette and corrected for dilution.

A. Spectrum of 2-aminobenzoyl-CoA monooxygenase/reductase before $(-)$ and on $(\cdots)$ addition of $62.7 \mu \mathrm{M}$ substrate.

B.Calculated difference spectra obtained on addition of $2.3 \mu \mathrm{M}, 8.9 \mu \mathrm{M}, 17.1 \mu \mathrm{M}, 25.4 \mu \mathrm{M}$, and $62.7 \mu \mathrm{M}$ 2-aminobenzoyl-CoA (substrate concentrations above $62.7 \mu \mathrm{M}$ resulted in a decrease of $\Delta$ absorbance at most wavelength). 


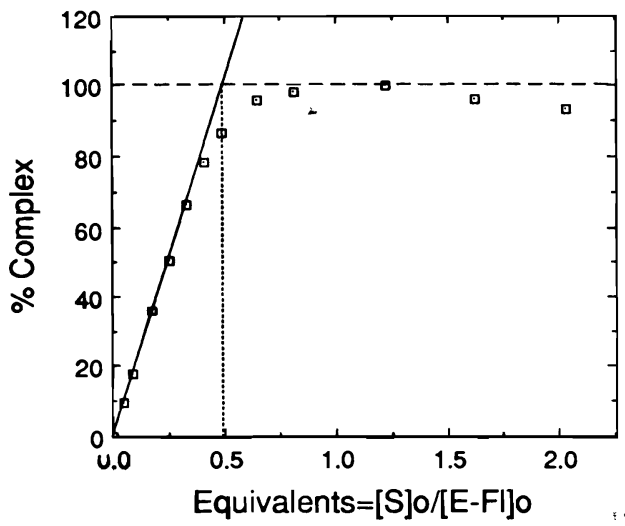

Figure 2. Plot of \%ES-complex (determined from $\Delta$ absorbance at $443 \mathrm{~nm}$ ) versus equivalents substrate added to the enzyme. Conditions as in Figure 1. The stoichiometry of 2aminobenzoyl-CoA/enzyme bound flavin $=0.5$ : 1 was estimated from the point of intersection of initial slope of ES-complex and maximal absorbance changes.

Kinetics of enzyme reduction and reoxidation

The course of reduction with NADH is also clearly biphasic as shown in Figure 3, one half of the enzyme reacting very fast (complete reaction within $<1 \mathrm{~min}$ ), the second half being reduced with a $t_{1 / 2} 12.5 \mathrm{~min}$. Reoxidation of reduced enzyme with either molecular oxygen (Figure 4) or NEM as electron acceptor again exhibits strongly biphasic reaction courses.

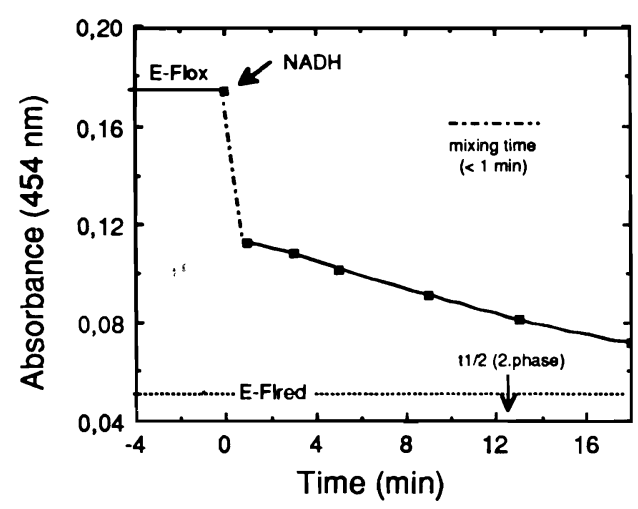

Figure 3. Course of reduction of 2-aminobenzoyl-CoA monooxygenase/reductase with NADH under anaerobic conditions. Conditions: $15.1 \mu \mathrm{M}$ enzyme, $50 \mathrm{mM}$ sodium phosphate, $\mathrm{pH} 7.4,0.2 \mathrm{mM}$ NADH; temperature $4^{\circ} \mathrm{C}$. Half-reduction within the mixing time (< 1 $\mathrm{min})$. The second phase occurs with a $\mathrm{t}_{1 / 2} \approx 12.5$ min (pseudo-first order approximation).

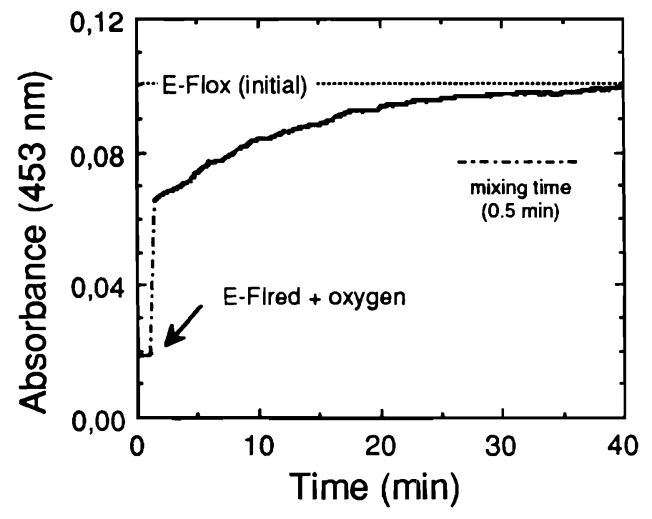

Figure 4. Course of reoxidation of photoreduced 2-aminobenzoyl-CoA monooxygenase/ reductase by $\mathrm{O}_{2}$. Conditions: $8.9 \mu \mathrm{M}$ enzyme, $50 \mathrm{mMNaPi}, \mathrm{pH} 7.4,12 \mathrm{mMEDTA} ; 4^{\circ} \mathrm{C}$. Upon admission of air into the anaerobic cuvette halfreoxidation is observed within the mixing time of $(<0.5 \mathrm{~min})$. The second phase of the reaction yields $>98 \%$ reoxidized enzyme within $40 \mathrm{~min}$. 
Catalytic reaction with $\mathrm{N}$-ethylmaleimide (NEM)

NEM is an artificial substrate for the enzyme, being converted to NES in the presence or absence of oxygen. This finding suggests a strict separation between the two reaction parts and provides a possibility for uncoupling substrate reduction from hydroxylation steps. Steady state analysis of 2-aminobenzoyl-CoA monooxygenase/reductase, varying both NEM and NADH concentrations yields a series of parallel Lineweaver-Burk plots (not shown), suggesting a ping pong mechanism (Scheme 1). The kinetic constants determined from these plots were $\mathrm{K}_{\mathrm{m}}(\mathrm{NADH})=$ $26 \mu \mathrm{M}, \mathrm{K}_{\mathrm{m}}(\mathrm{NEM})=0.47 \mathrm{mM}$ and $\mathrm{V}_{\max }=5650 \mathrm{~min}^{-1}$.

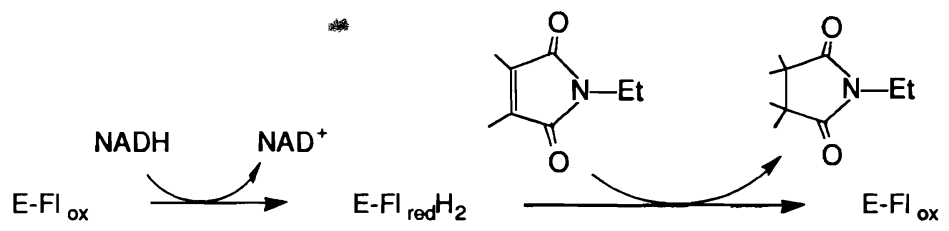

Scheme 1. Mechanism for the reaction of 2-aminobenzoyl-CoA monooxygenase/reductase with NEM.

\section{Conclusions}

Half-site reactivities observed in binding, reduction and reoxidation experiments suggest that 2aminobenzoyl-CoA monooxygenase/reductase is an unusual flavin-dependent hydroxylase, although some properties common to this class of enzymes were found.However, it cannot be concluded yet, whether the two subunits of the dimeric enzyme catalyze independently one part of the reaction (hydroxylation or reduction) or are involved both in all steps of catalysis.

\section{References}

1. Langkau, B., S. Ghisla, R. Buder, K. Ziegler, G. Fuchs: Eur. J. Biochem.(in press)

2. Strickland, S., V. Massey. 1973. J. Biol. Chem. 248, 2944.

3. Spector, T., V. Massey. 1972. J. Biol. Chem. 247, 4679.

4. Massey, V., F. Müller, R. Feldberg, M. Schuman, P.A. Sullivan, L.G. Howell, S.G. Mayhew, R.G. Matthews, G.P. Foust. 1969. J. Biol. Chem. 244, 3999.

5. Buder, R., G. Fuchs. 1989. Eur. J. Biochem. 185, 629. 